\title{
Administration of Pure Ergothioneine to Healthy Human Subjects: Uptake, Metabolism, and Effects on Biomarkers of Oxidative Damage and Inflammation
}

\author{
Irwin K. Cheah,,3 Richard M.Y. Tang, ${ }^{1,3}$ Terry S.Z. Yew, ${ }^{1,3}$ Keith H.C. Lim, ${ }^{2}$ and Barry Halliwell ${ }^{1,3}$
}

\begin{abstract}
Aim: We investigated the uptake and pharmacokinetics of L-ergothioneine (ET), a dietary thione with free radical scavenging and cytoprotective capabilities, after oral administration to humans, and its effect on biomarkers of oxidative damage and inflammation.

Results: After oral administration, ET is avidly absorbed and retained by the body with significant elevations in plasma and whole blood concentrations, and relatively low urinary excretion ( $<4 \%$ of administered ET). ET levels in whole blood were highly correlated to levels of hercynine and S-methyl-ergothioneine, suggesting that they may be metabolites. After ET administration, some decreasing trends were seen in biomarkers of oxidative damage and inflammation, including allantoin (urate oxidation), 8-hydroxy-2'-deoxyguanosine (DNA damage), 8-iso-PGF2 $\alpha$ (lipid peroxidation), protein carbonylation, and C-reactive protein. However, most of the changes were non-significant.

Innovation: This is the first study investigating the administration of pure ET to healthy human volunteers and monitoring its uptake and pharmacokinetics. This compound is rapidly gaining attention due to its unique properties, and this study lays the foundation for future human studies.

Conclusion: The uptake and retention of ET by the body suggests an important physiological function. The decreasing trend of oxidative damage biomarkers is consistent with animal studies suggesting that ET may function as a major antioxidant but perhaps only under conditions of oxidative stress. Antioxid. Redox Signal. 26, 193-206.
\end{abstract}

Keywords: ergothioneine, antioxidant, thione, oxidative damage, human study

\section{Introduction}

$\mathbf{L}$ -ERGOTHIONEINE (ET; Fig. 1), named after the ergot fungus from which it was first identified, is a unique, naturally occurring thiol derivative of histidine $(10,56)$. The de novo synthesis of ET has only been observed in a handful of organisms, namely Actinobacteria (e.g., Mycobacterium spp.) and certain non-yeast fungi $(18,19)$. Despite this, ET is widely present in animals, and it has been shown to accumulate at relatively high concentrations in certain cells and tissues of humans from diet $(10,16,40)$ by the action of an organic cation transporter novel type-1, OCTN1 (23). Studies have shown that when animals are supplemented with ET, it is avidly retained and accumulated in certain cells and organs, with a relatively slow clearance from the body $(32,39)$.

\section{Innovation}

Our study details the first administration, to our knowledge, of pure L-ergothioneine (ET) to human subjects and describes its uptake, accumulation, and possible metabolites. Despite limited effects of ET administration on oxidative damage and inflammatory biomarkers in these healthy subjects, the substantial accumulation by blood cells coupled with numerous in vivo studies demonstrating cytoprotective capabilities highlight the possible latent defensive potential of ET for situations when the body is under stress. In addition, this study helps to demonstrate the safety of ET for administration to humans and lays the foundation for future efficacy studies.

\footnotetext{
${ }^{1}$ Department of Biochemistry, Yong Loo Lin School of Medicine, National University of Singapore, Singapore.

${ }^{2}$ Department of Radiation Oncology, National University Cancer Institute Singapore, National University Hospital, Singapore.

${ }^{3}$ Centre for Life Sciences, National University of Singapore, Singapore.
} 
A L-ergothioneine (thione-thiol tautomers)<smiles>C[N+](C)(C)[C@H](Cc1[nH]c(=S)[nH]c1[O-])C(=O)[O-]</smiles>

B L-hercynine<smiles>C[N+](C)(C)[C@H](Cc1cnc[nH]1)C(=O)[O-]</smiles>

D L-ergothioneine sulfonate<smiles>C[N+](C)(C)[C@H](Cc1cnc(S(=O)(=O)[O-])[nH]1)C(=O)[O-]</smiles>

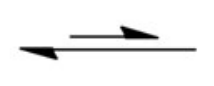<smiles>C[N+](C)(C)[C@H](Cc1c[nH]c(S)n1)C(=O)[O-]</smiles>

C S-methyl-L-ergothioneine<smiles>CSc1ncc(C[C@H](C(=O)[O-])[N+](C)(C)C)[nH]1</smiles>

FIG. 1. Structure of ergothioneine and possible metabolites. ET (A) exists as a thiol-thione; however, at physiological $\mathrm{pH}$, the thione tautomeric form is favored, conferring greater stability. The structures for precursor and possible metabolic derivatives, hercynine (B), S-methylergothioneine (C), and ergothioneine sulfonate (D) are also shown. ET, Lergothioneine.
However, to our knowledge, no studies have investigated the pharmacokinetics of pure ET administered to humans.

Although the physiological function of ET is not yet fully established [reviewed in Cheah and Halliwell (10)], numerous in vitro studies have demonstrated multiple potential beneficial properties (summarized in Supplementary Fig. S1; Supplementary Data are available online at www.liebertpub .com/ars). These include the ability to scavenge reactive oxygen species (ROS) such as hydroxyl radicals, hypochlorous acid, peroxynitrite, and singlet oxygen at high rates $(1-3,5$, $10,26)$ and to modulate inflammatory responses induced by treatment of cells with $\mathrm{H}_{2} \mathrm{O}_{2}$, tumor necrosis factor- $\alpha$, or palmitic acid $(33,46)$. In these studies, ET was able to dose dependently inhibit synthesis of pro-inflammatory cytokines, interleukin (IL)-6, and IL-8, and prevent cell death through inhibition of the pro-apoptotic factors Bax and caspase-3, likely mediated by preventing the activation of $\mathrm{p} 38$ and $\mathrm{NF}-\kappa \mathrm{B}(13,33,46)$.
ET has also been shown to protect against UV and gamma radiation by neutralizing radiation-induced ROS and possibly also by the activation of Nrf2 (increased Nrf2 and decreased Keap-1 expression) and downstream antioxidant genes (28, $30,38,44)$. ET has also been demonstrated to chelate divalent metal ions $(27,42)$, forming complexes with metal cations, including $\mathrm{Fe}^{2+}$ and $\mathrm{Cu}^{2+}$, that prevent their involvement in redox cycling $(16,65)$. The selective expression of slc22a4 (encoding the ET transporter, OCTN1) and the consequential presence of ET in organs and cells that are prone to oxidative stress and inflammation further hint at a possible cytoprotective physiological role for ET $(12,25)$.

In addition, studies in various animal models have demonstrated antioxidant and cytoprotective actions of ET, including protection against ischemia-reperfusion injury (6, 50), acute lung injury (48), damage caused by the pro-oxidants ferric-NTA (14) and $\beta$-amyloid (63), and D-galactose-induced

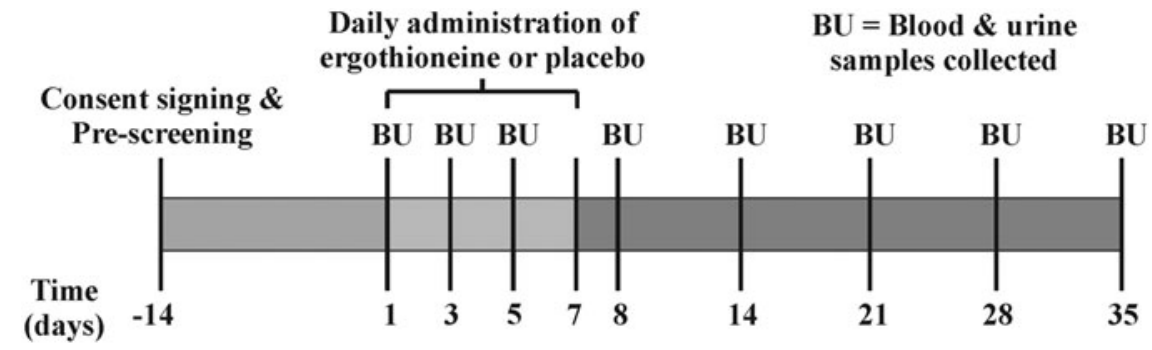

FIG. 2. Study design. Screening took place 14 days before enrolment of those subjects who met the inclusion/ exclusion criteria. Administration of ET ( 5 or $25 \mathrm{mg}$ ) or placebo took place daily for the first 7 days. Blood and urine samples were collected on days $1,3,5$, $8,14,21,28$, and 35. Subjects were asked to abstain from ET-rich food for the entire duration of the study. 
dementia (55). Mice lacking the ET transporter $\left(\mathrm{OCTN}^{-1-}\right)$, leading to absence of ET in cells and tissues, are predisposed to oxidative stress and inflammation (32). We have hypothesized that the presence and regulation of the transporter may be a defense mechanism by the body to slow pathology of

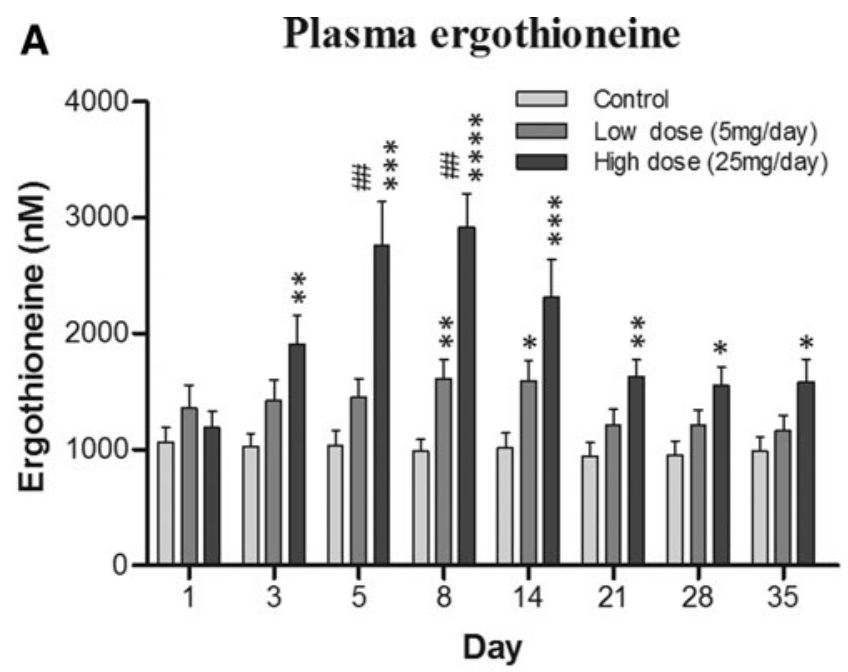

\section{B Whole blood ergothioneine (subtraction from baseline)}

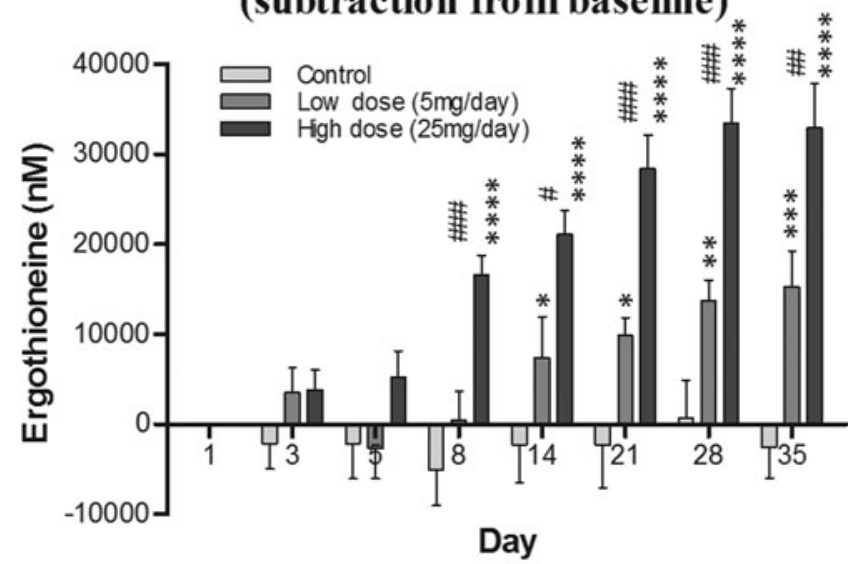

C

\section{Urinary ergothioneine (normalized to creatinine)}

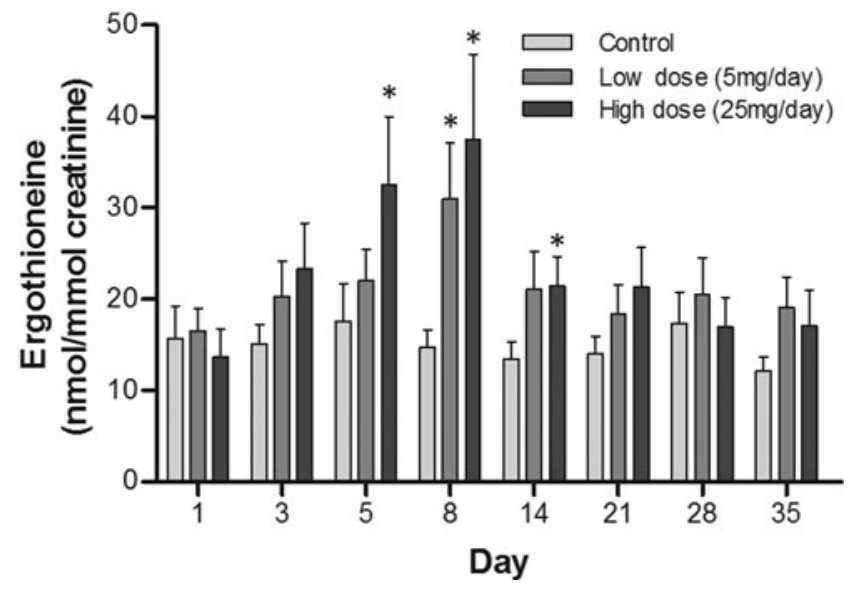

various disorders $(12,25)$, and its absence may predispose the body to increased risk of disease or acceleration of disease pathology, such as age-related neurodegeneration (9).

Here, to our knowledge, we report the first placebocontrolled study investigating the pharmacokinetics of pure ET in healthy human volunteers and examining the potential effects on selected biomarkers of oxidative damage and inflammation.

\section{Results}

\section{Screening and enrolment of subjects}

Of the 57 subjects screened, 47 were enrolled but only 45 successfully completed the study. Two subjects withdrew due to compliance failure. Enrolled subjects met all inclusion criteria and provided full informed consent to participate.

\section{Uptake and clearance of ET in blood and urine}

The levels of ET were quantified in whole blood, plasma, and urine samples from each subject both during the ET administration (days 1, 3, 5, and 8) and post-administration (days 14, 21, 28, and 35), to assess uptake and clearance of ET (Fig. 2). Plasma levels (Fig. 3A) dose dependently increased during the administration period (day 1-7) and then gradually declined until day 35 , although for subjects on the high dose, these levels remained significantly higher than for controls $(p<0.05)$. Likewise, excretion of ET (urinary ET levels; Fig. 3C) followed a similar pattern to plasma levels, increasing during the first 8 days and then steadily declining post-administration, although at day 35 the ET levels still tended to be above those in the control group.

By comparison, plasma and whole blood ET levels increased much more than urine during the ET administration (at day 8, the increase in ET concentration relative to controls was $\sim 2000 \mathrm{n} M$ and $\sim 125,000 \mathrm{n} M$ vs. $\sim 400 \mathrm{n} M$, for plasma, whole blood, and urine, respectively), indicating a high level of ET retention by the body. In contrast, whole blood ET levels (Fig. 3B) continued to increase gradually over the entire duration of the study, reaching maximal levels around day 28. The levels of ET in plasma, urine, and whole blood demonstrate a dose-dependent increase.

FIG. 3. Plasma, whole blood, and urinary levels of ergothioneine. The levels of ET in plasma (A), whole blood (B), and urine $(\mathbf{C})$ of the subjects from each group were quantified by using LC-MS/MS. Since basal values of ET varied greatly between subjects, the whole blood values are represented as the difference in ET levels from day 1 (study commencement). Plasma concentrations of ET rapidly increased during the administration phase (first week), followed by a gradual decline in the subsequent weeks; however, concentrations of ET in whole blood continued to increase long after administration of ET had ceased and only plateaued or began to decline at day 35. Urinary excretion of ET increased during administration of the compound and gradually declined after this. $* p<0.05$, $* * p<0.01, * * * p<0.001$, and $* * * * p<0.0001$ versus control; ${ }^{\#} p<0.05,{ }^{\# \#} p<0.01$, and ${ }^{\# \# \#} p<0.001$ versus low-dose, MannWhitney test. LC-MS/MS, liquid chromatography tandem mass spectrometry. 
Plasma, whole blood, and urinary levels of hercynine, S-methyl-ET, and $\mathrm{ET}-\mathrm{SO}_{3} \mathrm{H}$

Little is known about the oxidation products of ET in vivo, though some groups $(31,54)$ have investigated the possible reaction products in vitro. Earlier studies demonstrated the reversible oxidation of ET to the disulfide under certain laboratory conditions, although under physiological conditions ET remains in the thione state (29). However, the nature of the ET-disulfide, if formed in vivo, is vastly different from that of glutathione disulfide, possessing an extremely high redox potential. Depending on the presence or absence of other thiols such as reduced glutathione (GSH), ET-disulfide can be reduced back to ET or may spontaneously disproportionate to ET and its sulfenic acid derivative (ET-SOH), respectively (31). The latter may be oxidized further to the highly unstable ET sulfinic acid $\left(\mathrm{ET}-\mathrm{SO}_{2} \mathrm{H}\right)$ or to the very stable sulfonic acid derivative $\left(\mathrm{ET}-\mathrm{SO}_{3} \mathrm{H}\right)(31,54)$.

Decomposition of the unstable ergothioneine sulfinate will generate hercynine (Fig. 1B), which is also an intermediary precursor in ET biosynthesis. Unlike the sulfinic acid, ETsulfonate (Fig. 1D) is more stable and hence able to be measured as a possible oxidation product of ET. S-methyl-ET (Fig. 1C) could be generated through the methylation of the sulfur.

We thus investigated the levels of hercynine, ET- $\mathrm{SO}_{3} \mathrm{H}$, and S-methyl-ET in plasma, whole blood, and urine samples from subjects with and without ET administration. The levels of hercynine in plasma (average basal level 14.6 $\pm 0.5 \mathrm{n} M$ ) and whole blood (average basal level 290.2 $\pm 12.3 \mathrm{n} M$ ) were about 85 and 350 times lower than ET levels (average basal plasma level $1281.8 \pm 81.0 \mathrm{n} M$ and whole blood level $101.2 \pm 6.0 \mu M)$, respectively. On the other hand, urinary hercynine levels (average basal level $44.7 \pm 2.4 \mathrm{n} M$, normalized to creatinine) were about 2.5 times higher than urinary ET levels (average basal level $15.0 \pm 0.8 \mathrm{n} M$, normalized to creatinine). No obvious trends were observed in plasma and urinary levels of hercynine (Fig. 4A, F); however, the whole blood levels of hercynine (Fig. 4C, D) were significantly elevated in subjects administered low- or high-dose ET.

The levels of S-methyl-ET were even lower than hercynine, with plasma (average basal level $7.0 \pm 0.4 \mathrm{n} M$ ) and whole blood (average basal level 222.7 $\pm 10.8 \mathrm{n} M$ ) levels about 180 and 450 times lower than ET, respectively. Urinary levels of S-methyl-ET were very similar to urinary hercynine, with an average basal level around 42.6 $\pm 1.9 \mathrm{nM}$. S-methylET was dose dependently elevated in plasma, whole blood, and urine (Fig. 4B, E, and G) and followed a similar trend to ET levels in the respective samples. That is, plasma and urinary S-methyl-ET increased during the administration period until day 8 and then gradually declined. Meanwhile, whole blood levels continued to increase for the duration of the study. Levels of ET-SO $\mathrm{S}_{3}$ in plasma, whole blood, and urine were at the limit of quantification $(\sim 5 \mathrm{n} M)$; hence, analysis was not possible.

\section{Correlation of ET with hercynine and S-methyl-ET}

We noted that the levels of hercynine and S-methyl-ET followed similar trends to the levels of ET in plasma, whole blood, and urine and, therefore, investigated the correlation between them. Using the data from all groups (control, lowand high-dose ET), we identified a highly significant $(p<0.0001)$ correlation of both whole blood hercynine (Fig. 5A) and S-methyl-ET (Fig. 5B) with ET levels, with Pearson's correlation coefficient ( $r$ ) being 0.8915 and 0.9614 , respectively.

\section{Effect of ET supplementation on the oxidative damage biomarkers allantoin and 8-hydroxy-2'-deoxyguanosine}

The possible modulation of oxidative damage by ET supplementation was investigated by using the oxidative biomarkers [by-products of oxidative damage to biomolecules (26)], allantoin and 8-hydroxy-2'-deoxyguanosine $(8 \mathrm{OHdG})$, which are oxidation products of urate and deoxyguanosine, respectively.

Since humans do not possess a urate oxidase enzyme, urate is the end product of purine catabolism; however, urate can be non-enzymatically converted to allantoin by certain ROS. Allantoin levels can be measured in both plasma and urine and have been widely used as indicators of oxidative stress in vivo $(21,22,53)$. Plasma allantoin levels tended to decrease after day 21 with low- and high-dose ET supplementation (Fig. 6A); however, this was not significant. Urinary allantoin levels also demonstrated a clear declining trend with ET supplementation (Fig. 6B). However, allantoin levels were only significantly lower in the low-dose ET group relative to placebo controls at day $35(p<0.05)$.

The oxidation of the nucleoside deoxyguanosine in nuclear and mitochondrial DNA, and in the DNA precursor pool, can generate $8 \mathrm{OHdG}$, one of the most frequently measured DNA damage products (24), which can be easily measured in urine (26). Levels of urinary $8 \mathrm{OHdG}$ have been suggested to be an "indicator" of oxidative burden; elevated levels are often linked with disorders such as cancer, atherosclerosis, diabetes (62), and neurodegeneration (64) and are also elevated in individuals who are subjected to extraneous toxins, such as smokers (53). The urinary levels of $80 \mathrm{HdG}$ levels (normalized to creatinine) appeared lower in ET-treated groups

FIG. 4. Plasma, whole blood, and urinary levels of hercynine and S-methyl ergothioneine. The levels of hercynine and S-methyl ergothioneine were assessed in plasma, whole blood, and urine samples. No significant differences were seen in plasma (A) and urinary hercynine (F) after ET administration. After subtracting baseline levels of hercynine, an increasing trend was seen in whole blood hercynine $(\mathbf{C}, \mathbf{D})$ levels similarly to whole blood ET, continuing to increase until day 35. Plasma (B) and urinary (G) S-methyl ET levels appear to follow a similar trend to their respective ET levels with an initial increase during the administration phase, with the highest levels in the high-dose group at day 8 , and then declining gradually. Levels within the administration group did not differ significantly in plasma, but urinary S-methyl ET levels were significantly elevated in the high-dose group at the final time point. Whole blood S-methyl ET (E) follows a similar trend to whole blood ET, with a trend to increasing levels up to day 35 ; however, no significance was observed. ${ }^{*} p<0.05$, $* * p<0.01, * * * p<0.001$ versus control; ${ }^{\#} p<0.05$ versus low dose, Mann-Whitney test. 
A

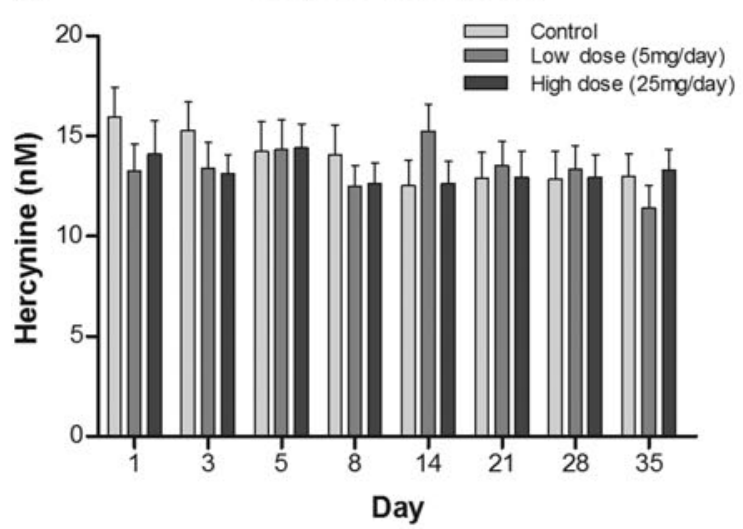

C

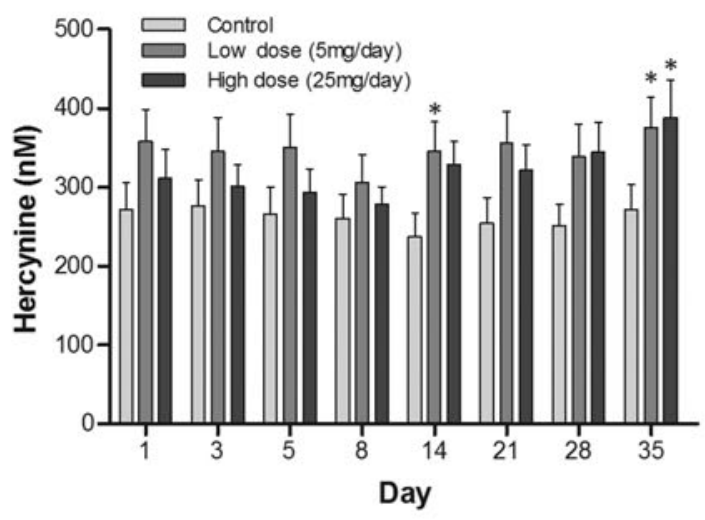

E

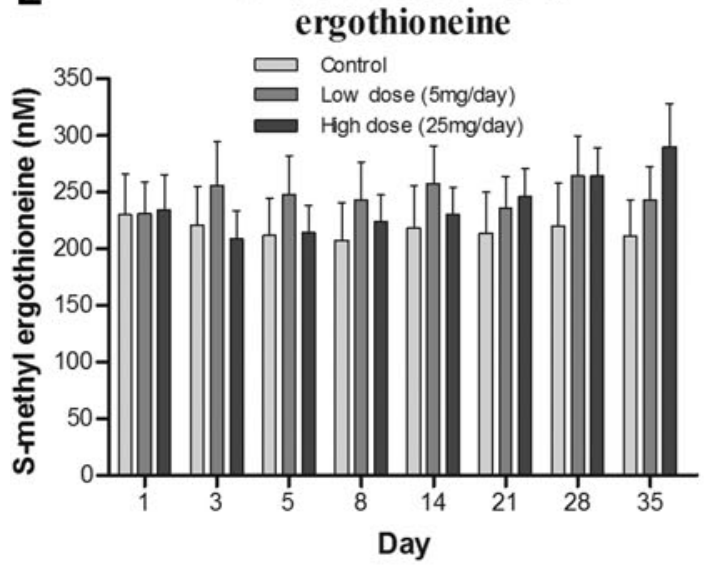

B Plasma S-methyl ergothioneine

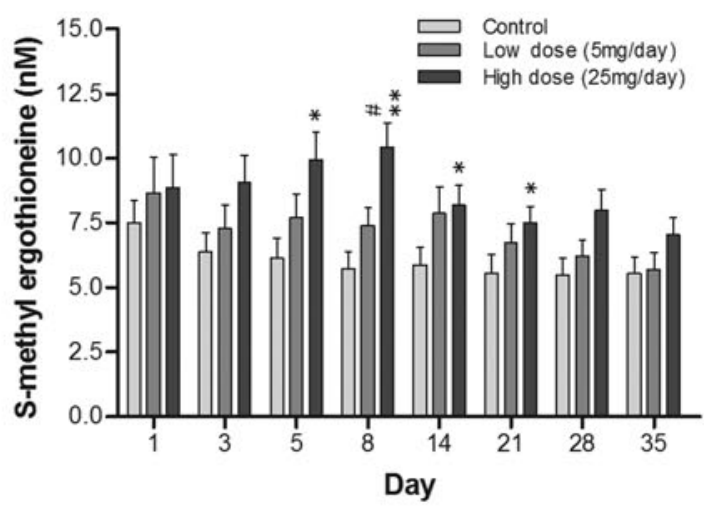

D Whole blood hercynine (subtraction from baseline)

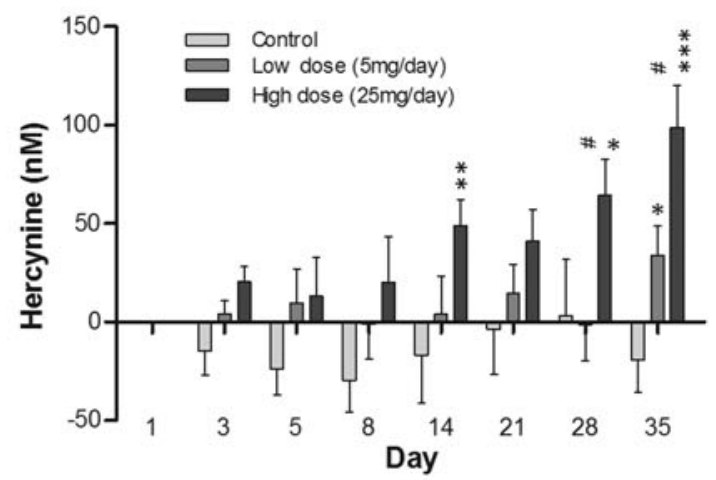

$\mathbf{F}$

Urinary hercynine (normalized to creatinine)

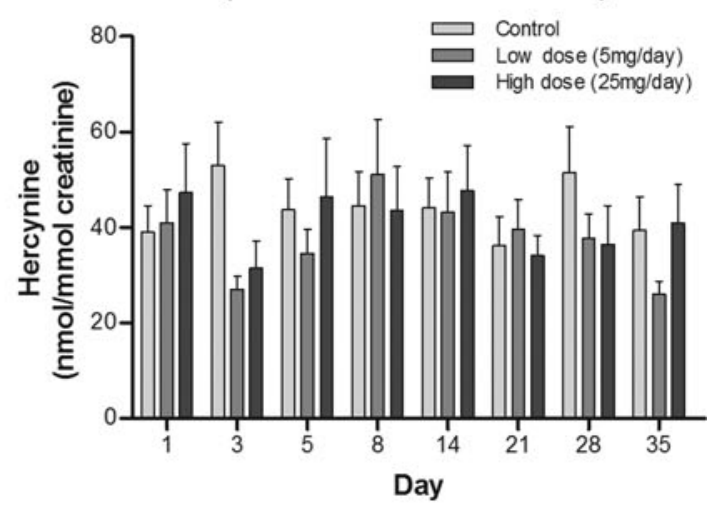

G Urinary S-methyl ergothioneine

(normalized to creatinine)

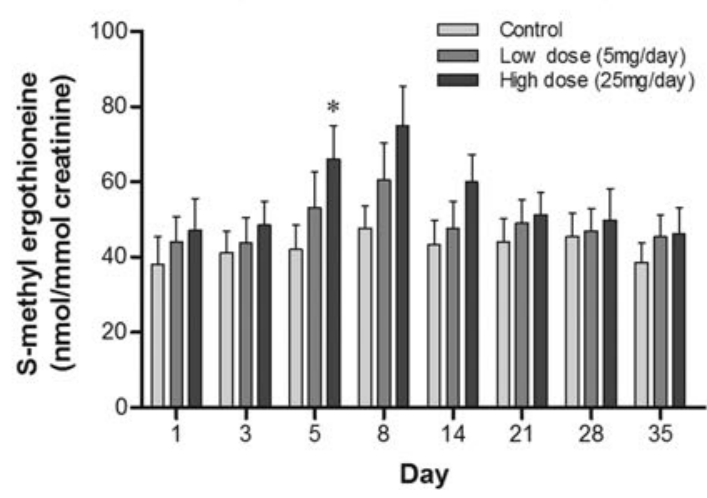



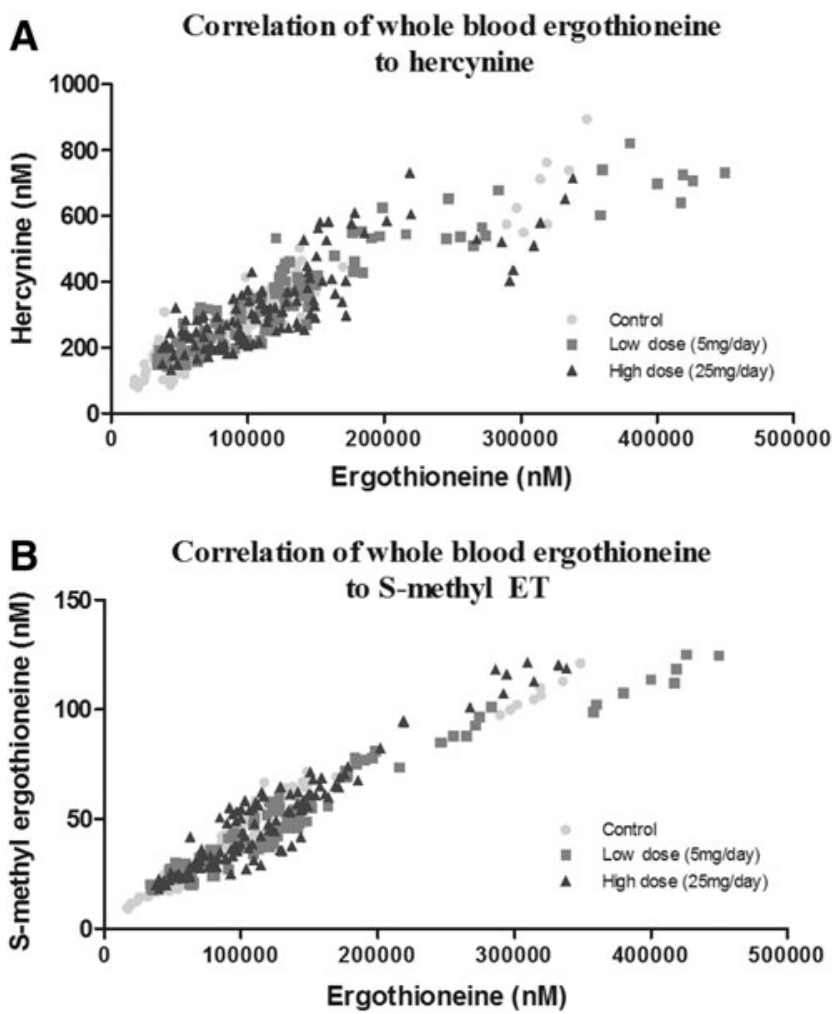

FIG. 5. Correlation of ergothioneine and hercynine and S-methyl ergothioneine levels in whole blood. The levels of hercynine and S-methyl ET correlated with those of ET in whole blood. Both hercynine (A) and S-methyl ET (B) were significantly $(p<0.0001)$ correlated to ET in whole blood, with Pearson's coefficient $r$ values of 0.8915 and 0.9614 , respectively.

(Fig. 7), particularly at days 8 and 14; however, this was again not statistically significant.

\section{Effect of ET supplementation on levels of plasma protein carbonyls}

Levels of protein carbonyls [an indicator of oxidative damage to proteins (26)] were measured in the plasma samples. No significant differences were observed in plasma protein carbonyl levels between controls and ET administration groups (Fig. 8A). A large variation between time points was noted.

\section{Effect of ET supplementation on urinary levels of $F_{2}$-isoprostanes}

$\mathrm{F}_{2}$-isoprostanes (8-iso prostaglandin $\mathrm{F}_{2 \alpha} ; \mathrm{F}_{2}$-IsoPs) produced by non-enzymatic peroxidation of arachidonic acid are widely used biomarkers of oxidative damage in humans (41). Urinary $\mathrm{F}_{2}$-IsoPs were extracted by solid-phase extraction [modified from Lee et al. (34)], and levels were measured by liquid chromatography tandem mass spectrometry (LC-MS/ MS). Although a decreasing trend of urinary $\mathrm{F}_{2}$-IsoPs was seen with increasing administration of ET (Fig. 8B), this was borderline non-significant (one-way analysis of variance; $p=0.0686$ ). Levels of $\mathrm{F}_{2}$-IsoPs seemed to decrease, especially toward days $28-35$ of the study, corresponding to the days with the highest whole blood ET.
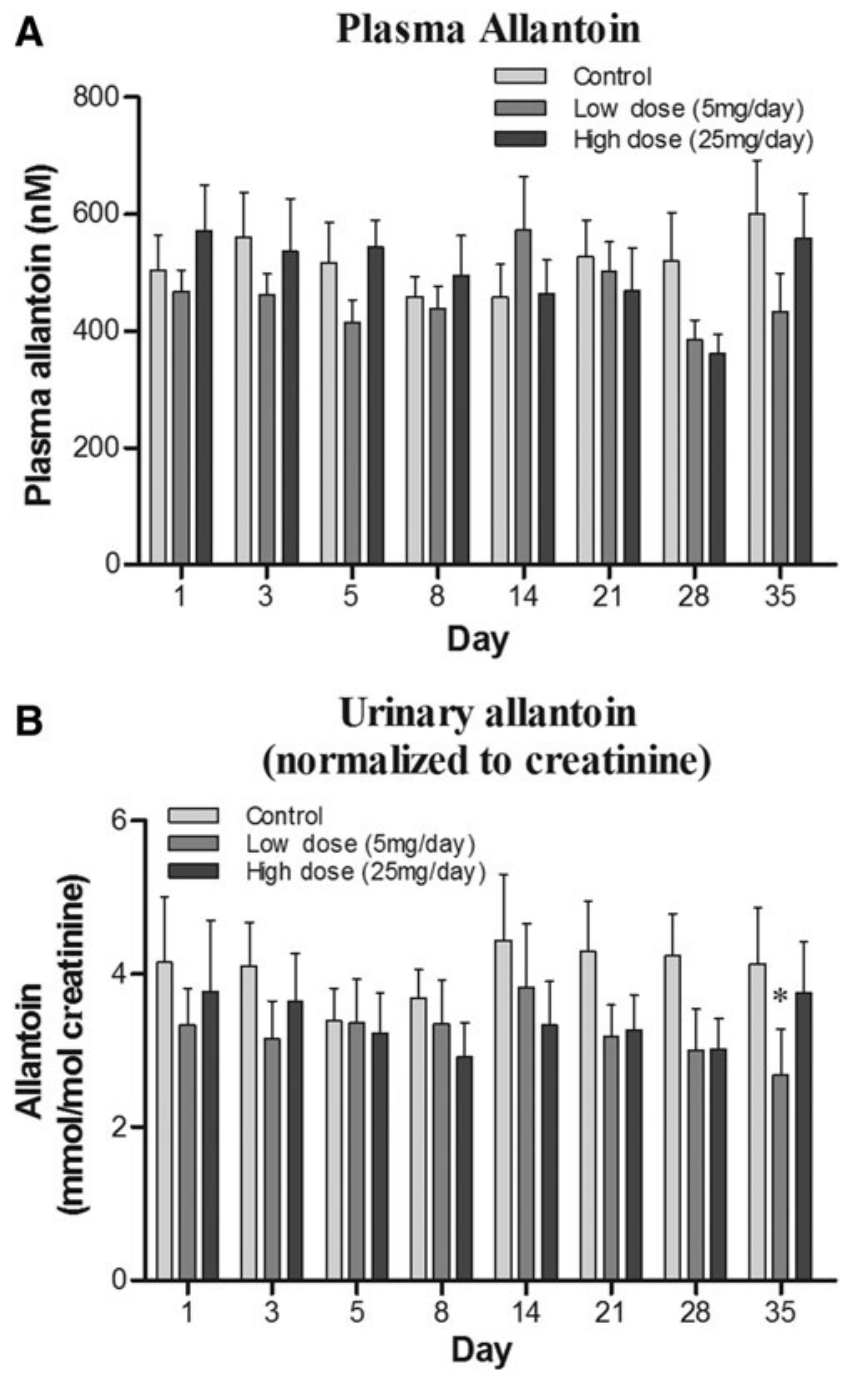

FIG. 6. Effect of ergothioneine on basal levels of plasma and urinary allantoin. The levels of the oxidative damage marker allantoin, generated by oxidation of urate in humans, were measured in the plasma (A) and urine (B) of subjects. Although urinary allantoin levels appear to be lower in the subjects supplemented with ET, no significant differences were observed in both plasma and urinary levels of allantoin, with the exception of day 35, low dose $(* p<0.05)$.

\section{Effect of ET supplementation on plasma levels of $C$-reactive protein}

C-reactive protein (CRP) is a sensitive indicator of inflammatory status, and elevated levels of CRP are associated with multiple disorders involving inflammation. We investigated whether administration of ET affected the plasma levels of CRP. No differences were observed between the control and ET-supplemented groups (Fig. 8C); however, the large inter- and intra- (day to day) subject variation in CRP levels could have obscured any trends.

\section{$E T$ tolerance and clinical parameters}

No significant differences were observed in both liver function tests and lipid profiles for the duration of the study 


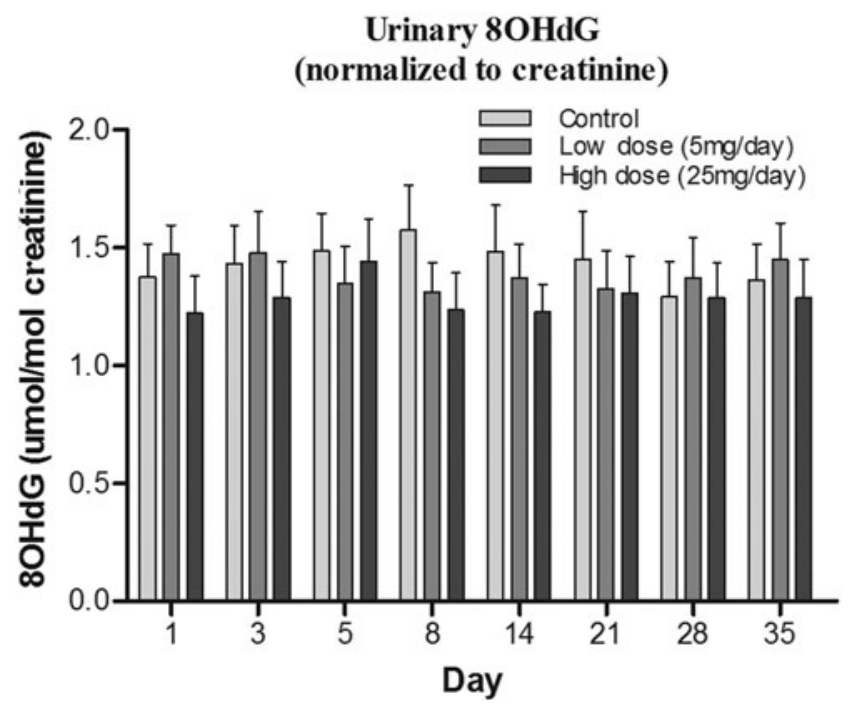

FIG. 7. Effect of ergothioneine on basal levels of urinary 8-OHdG. After oxidative damage to DNA or its precursor pool, the body repairs the damage by excising the base damage products, which are excreted. Levels of the DNA damage marker, $8-\mathrm{OHdG}$, were measured in the urine. No significant changes were observed in urinary 8-OHdG levels between ET-administered and control subjects. 8OHdG, 8-hydroxy-2'-deoxyguanosine.

(clinical parameters were taken at the commencement and conclusion of the study; data not shown). No adverse effects were noted from administration of ET throughout the study. Subjects on routine visits reported no side-effects from administration of ET or placebo.

\section{Discussion}

Numerous studies in vitro, and some in vivo, have demonstrated the uptake and accumulation of ET, and its possible antioxidant and cytoprotective benefits (10). A few studies $(58,61)$ have evaluated the bioavailability of ET after consumption of mushrooms, which contain high levels of ET (16), by humans. No studies to date have evaluated the uptake

FIG. 8. Effect of ergothioneine supplementation on plasma protein carbonyl content, urinary $F_{2}$-IsoPs, and plasma CRP. Although there was a trend toward lower protein carbonyls in ET-administered groups (A), no significant differences were observed between any the ETtreated groups and controls. $\mathrm{F}_{2}$-IsoPs (41), stable oxidation products of arachidonic acid, were measured to investigate whether ET supplementation was able to modulate lipid peroxidation. $\mathrm{F}_{2}$-IsoPs levels in urine (B) displayed a slightly decreasing trend with ET administration; however, this was borderline non-significant $(p=0.0686$; one-way analysis of variance). Levels of CRP were measured via enzyme-linked immunosorbent assay (C) to determine whether ET administration could modulate these levels. No significant difference was observed between levels of CRP between ET administration groups and controls; however, a large amount of variation was observed between subjects within the same group. CRP, C-reactive protein; $\mathrm{F}_{2}$-IsoP, $\mathrm{F}_{2}$-isoprostanes. of pure ET in humans. The present study, thus, sought to evaluate the dose-dependent uptake and accumulation of ET after daily oral administration of 5 or $25 \mathrm{mg}$ ET for 7 days, and its clearance and possible beneficial effects over the subsequent 28 days.

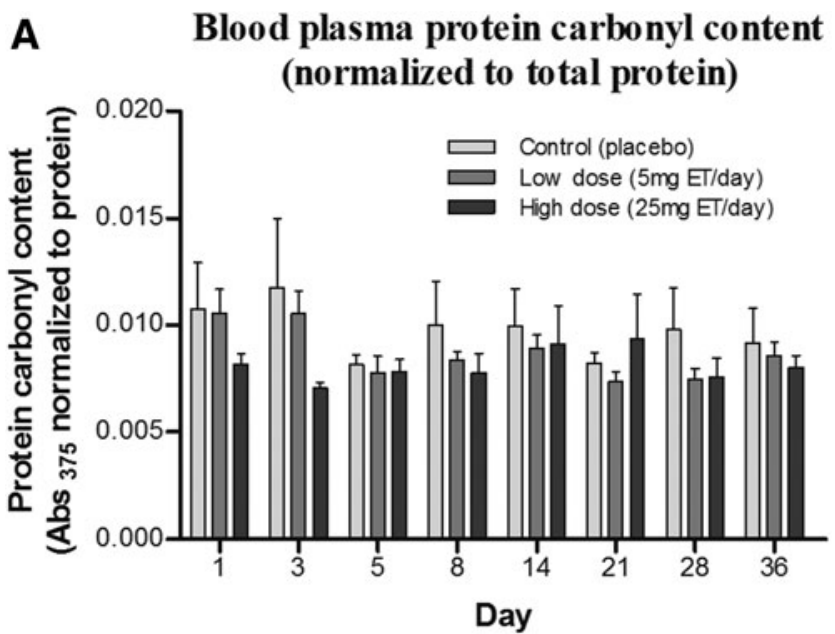

B
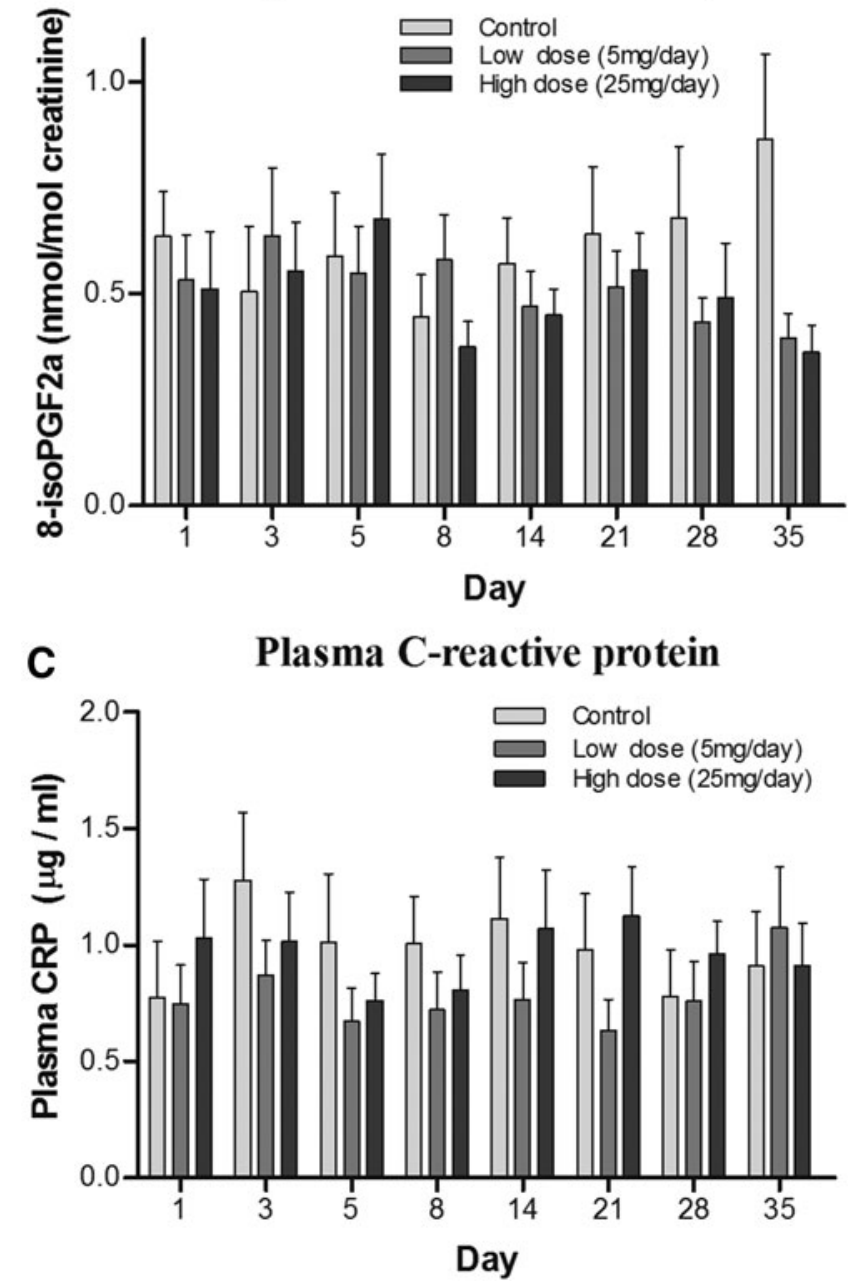


\section{Uptake and accumulation of ET}

Our data demonstrate that ET is avidly taken up and retained by the human body. The levels of ET in plasma were significantly elevated during the administration period in a dose-dependent manner and gradually declined in the weeks after the final administration. However, even after 4 weeks, the average plasma ET levels in the high-dose group were still greater than the basal levels at the commencement of the study. In contrast to the plasma levels, the whole blood ET concentrations (presumably consisting of mostly erythrocyte ET) do not appear to be significantly elevated during the administration period, but they steadily increase up to 4 weeks after the administration has ceased.

Levels of ET in urine were seen to increase with dose and time of ET administration. However, the overall excretion of ET remained low compared with the levels of ET in plasma and whole blood, indicating that ET is predominantly absorbed and retained by the body after oral administration. Based on an average urine output of $800-2000 \mathrm{ml} /$ day in adults, we calculated that the estimated percentage ET excretion over the duration of the study was only $1.4-3.7 \%$ and $0.7-1.9 \%$ of the total ET administered in low- and high-dose subjects, respectively. Since both excreted ET and whole blood levels remain relatively low during the administration phase, this may suggest that ET is primarily accumulated at another tissue or organ in the body. A gradual release of ET from this site(s) could explain the continual steady increase in whole blood for weeks beyond the administration phase.

Studies investigating the uptake of ET in mice demonstrated that liver ET levels increased much faster than in blood (Cheah et al., manuscript in preparation), which may indicate that the liver could be a site for ET accumulation and storage in humans. Another possible site could be the bone marrow, which has a high expression of OCTN1 mRNA (23). Indeed, ET has been suggested to be involved in erythropoiesis (43), possibly leading to the incorporation of higher levels of ET in erythrocytes. In addition, erythrocytes might take up plasma ET; hence, the limited excretion despite the decline in plasma ET after administration ceases.

\section{Variation in basal ET levels}

Despite the strict inclusion and exclusion criteria for the study, screening subjects for gender, age, and race and exclusion of subjects with abnormal clinical parameters such as cholesterol and lipid profiles, liver problems, or elevated blood pressure, the variability in basal levels of ET between the subjects was astoundingly different, with up to a 15-fold difference between the highest and lowest basal levels (Fig. 9A). Furthermore, subjects were asked to abstain from ET-rich foods for 2 weeks before the commencement of the study to minimize effects of diet. However, since low levels of ET exist in a wide range of foods (16), this makes it difficult to completely avoid ET uptake. Therefore, these differences could, in part, be due to a long washout period (greater than 4 weeks as shown in these studies) and differences in diet.

The differences could also be due to polymorphisms of the gene SLC22A4, encoding the ET transporter, OCTN1, which might affect uptake and retention of ET. Indeed, looking more deeply at the uptake between the individuals with the highest and lowest ( $n=3 ; 25 \mathrm{mg}$ administration group) basal whole blood ET levels, we see that there is a significant
A

\begin{tabular}{|c|c|c|c|c|c|c|c|c|}
\hline & \multicolumn{8}{|c|}{ Control group } \\
\hline Subject \# & 1 & 2 & 3 & \begin{tabular}{|l|l|}
4 \\
\end{tabular} & \begin{tabular}{|l|}
5 \\
\end{tabular} & 6 & 7 & 8 \\
\hline \multicolumn{9}{|l|}{ Day } \\
\hline 1 & 169,690 & 19,345 & 43,121 & 314,407 & 137,774 & 98,469 & 106,122 & 117,157 \\
\hline 3 & 133,459 & 19,276 & 46,396 & 302,021 & \begin{tabular}{|l|}
139,507 \\
\end{tabular} & 107,012 & 109,148 & 110,404 \\
\hline 5 & 135,648 & 17,029 & 49,115 & 289,767 & 146,338 & 106,731 & 115,996 & 89,819 \\
\hline 8 & 120,352 & 25,509 & 47,790 & 319,728 & 149,646 & 93,762 & 90,148 & 101,204 \\
\hline 14 & 110,961 & 24,809 & 38,006 & 319,097 & 135,643 & 99,031 & 107,373 & 117,740 \\
\hline 21 & 115,593 & 16,711 & 43,465 & 335,379 & 128,938 & 98,866 & 118,079 & 87,000 \\
\hline 28 & 122,764 & 23,855 & 46,137 & 348,353 & 145,114 & 89,824 & 118,736 & 110,956 \\
\hline 35 & 131,027 & 24,343 & 45,972 & 297,076 & \begin{tabular}{|l|}
139,798 \\
\end{tabular} & 103,244 & 119,955 & 101,071 \\
\hline Subject \# & 9 & 10 & \begin{tabular}{|l|}
11 \\
\end{tabular} & 12 & 13 & 14 & 15 & \\
\hline \multicolumn{9}{|l|}{ Day } \\
\hline 1 & 127,518 & 35,696 & 33,761 & \begin{tabular}{|l|}
95,829 \\
\end{tabular} & 55,539 & 44,525 & 91,059 & \\
\hline 3 & 132,664 & 38,966 & 34,869 & 102,719 & 47,525 & 47,986 & 85,743 & \\
\hline 5 & 148,358 & 40,275 & 35,060 & 99,084 & 53,726 & 44,594 & 86,273 & \\
\hline 8 & 107,733 & 36,273 & 36,729 & 94,520 & 50,218 & 46,603 & 92,925 & \\
\hline 14 & 129,845 & 38,828 & 34,503 & 104,283 & 52,406 & 46,486 & 96,487 & \\
\hline 21 & 137,683 & 38,785 & 32,574 & 98,527 & 57,346 & 45,554 & 100,271 & \\
\hline 28 & 130,831 & 39,252 & 30,576 & 97,695 & 55,549 & 45,967 & 94,319 & \\
\hline 35 & 139,141 & 39,490 & 30,968 & 87,492 & 55,783 & 44,048 & 91,234 & \\
\hline
\end{tabular}

\section{B Comparis on of the increase in blood ET \\ between the 3 individuals with the lowest or highest bas al levels (25 mg ET adminis tration group)}

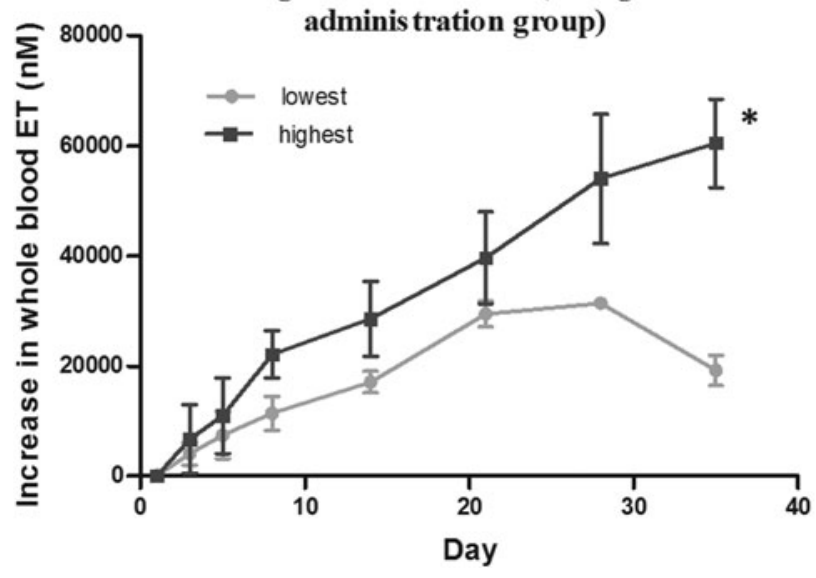

FIG. 9. Comparison of whole blood ET values between individuals and the difference in uptake between individuals of highest and lowest basal whole blood ET. Despite the subject selection criteria, there was a large variation in basal whole blood (presumably largely erythrocyte) ET levels, as can be seen by the whole blood ET of the control group (A) with up to a 15-fold difference between the lowest (light gray shading) and highest (dark gray shading) subjects. This might be partially accounted for by different transporter (SLC22A4) polymorphisms. Consistent with this, when comparing the increase in whole blood ET between individuals $(n=6)$ of the highest and lowest basal whole blood ET $(25 \mathrm{mg} /$ day ET administration group), there was a greater increase in the group with higher basal values (B), ${ }^{*} p<0.05$; Welch's $t$-test.

difference in uptake despite them being administered the same dose (Fig. 9B). Toh et al. (57) demonstrated that singlenucleotide polymorphisms of SLC22A4 can, indeed, alter the transport function of ET.

\section{Metabolites of ET}

Although ET sulfonate $\left(\mathrm{ET}-\mathrm{SO}_{3}\right)$ was detectable in some of the blood and urine samples, levels were unfortunately below the limits of quantification $(\sim 5 \mathrm{n} M)$. On the other hand, hercynine and S-methyl-ET were easily quantifiable and were found to very significantly correlate with whole 
blood ET levels $(p<0.0001)$, which suggests that these compounds are metabolites of ET. Indeed, studies have shown that hercynine (a precursor in the biosynthesis of ET) is also an oxidation product from the reaction of ET with certain ROS such as hypochlorite, peroxynitrite, hydrogen peroxide, and iron chloride $(4,54)$. Much less is known regarding the formation of S-methyl-ET; however, methyl halides (e.g., chloromethane, iodomethane) are able to react with GSH to form S-methylglutathione (47), involving glutathione-S-transferase. Although it is not known whether ET could undergo a similar reaction, if it did, it could generate S-methyl-ET.

Alternatively, the hercynine and S-methyl-ET could be derived from the metabolism of ET by gut microflora. However, it may be unlikely that microbiota are a major source of hercynine in the blood since the transport efficiency of hercynine by OCTN1 has been shown to be rather poor (20), and the levels of hercynine in plasma are significantly higher than in urine. On the other hand, levels of S-methylET in urine are far higher than in plasma, suggesting that this compound is a rapidly cleared by-product.

\section{Changes in biomarkers of oxidative damage}

Minimal differences (with the exception of $\mathrm{F}_{2}$-isoPs) were observed in the levels of various oxidative damage markers, and also the inflammatory biomarker CRP, between placebo and ET administration groups. The healthy young male volunteers selected for this study were without history of any medical conditions and habits, for example, smoking, which are known to elevate oxidative damage. Thus, our study provides only suggestive evidence that ET administration decreases oxidative damage to lipid, protein, DNA, and urate in these subjects, since for all of them there was a trend to a decrease, but usually not achieving significance.

Nevertheless, despite low levels of urinary $\mathrm{F}_{2}$-IsoPs in the young healthy male subjects, we observed a decreasing trend of $\mathrm{F}_{2}$-IsoPs with ET administration. Although this was borderline non-significant, the differences were the most pronounced toward the end point of the study, which corresponded to the point of the highest ET accumulation in the blood. Possibly, a significant decrease in biomarkers of oxidative stress from ET administration may have occurred if the study duration was longer or if the subjects had elevated oxidative stress, for example, elderly individuals (9), after strenuous exercise or in smokers (53).

Indeed, studies have revealed that when animals are placed under oxidative stress, for example, administration of ferricnitrilotriacetate (14), ischemia-reperfusion injury $(6,50)$, induced acute respiratory distress (48), or induced neurodegeneration $(55,63)$, ET supplementation was able to decrease oxidative stress and inflammation, and to increase survival. In the absence of the ET transporter, OCTN1, the knockout animals devoid of tissue ET also appear normal until placed under stress $(11,32,45)$.

Under physiological conditions, ET primarily exists as the thione tautomer. This unique property of ET could mean that under normal healthy circumstances, ET may not be preferentially utilized as an antioxidant when high levels of other basic endogenous antioxidants such as GSH [a primary antioxidant thiol in the body (26)] are present. Instead, it is possible that ET may come into play only when the body is placed under higher oxidative stress. We observed similar outcomes in our ET supplemented mice, where no significant changes in protein carbonyls could be seen in wild-type C57BL6 mice supplemented with high levels of ET, relative to saline-administered controls. However, when the mice were exposed to gamma irradiation, a significant decrease in protein carbonylation was observed in ET-treated animals (Cheah et al., unpublished data).

Indeed, we recently proposed that tissues may deliberately elevate levels of ET by increasing the expression of OCTN1 in response to stress or damage (25). The avid uptake and retention of ET despite the lack of obvious function in healthy individuals suggests that the body may store the ET until it is required, possibly as a defense mechanism. Under pathological conditions, these stores of ET may be activated or utilized at the sites of elevated ROS or tissue injury, as seen in animal studies.

It was previously shown that OCTN1 expression can be transcriptionally activated by RUNX1, inflammatory cytokines, and $\mathrm{NF} \kappa \mathrm{B}$ (37), and more recently, ET was shown to mediate cytoprotection through induction of Nrf2 and Hsp70 $(30,49)$. Moreover, ET has been shown to elevate the expression of glutathione reductase, catalase, and superoxide dismutase, while decreasing the expression of NADPH oxidase 1 (NOX), in human brain microvascular endothelial cells (35). Indeed, the upregulation of these "vitagenes" in hormetic pathways has been associated with a reduction in diseases related to oxidative stress, such as cancer and neurodegeneration $(7,8)$. NOX activity is recognized as a major source of ROS in the body, and these ROS are suggested to play a key role in the generation of $F_{2}$-IsoPs (60). Hence, if, indeed, ET downregulates NOX, this may, in part, explain the decreasing trend of urinary $\mathrm{F}_{2}$-IsoPs seen with ETadministered subjects, which will be explored in future work.

\section{Safety of ET}

Toxicology, studies in animals or bacteria have reported an absence of adverse effects from administration of ET (17, 51, 52). Likewise, in this study, there were no reported adverse effects from the administration of pure ET in humans. In addition, no changes were observed in liver function tests and lipid profiles (measured at commencement and conclusion of the study) from administration of ET.

\section{Conclusion}

The current study presents the first data from administration of pure ET supplements to humans. As with prior animal studies, we see that ET is avidly absorbed and retained by the body. Although minimal effects of ET were observed in inflammatory biomarkers and oxidative damage, a trend to a decrease in the latter was clear.

At this stage, it is not known whether ET supplementation in humans will benefit "at risk" individuals by modulation of oxidative stress and inflammation and whether lower basal levels of ET increase risk of disease (9). Further work will be needed to elucidate this.

\section{Materials and Methods}

\section{Chemicals, reagents, and investigational compound}

ET, L-ergothioneine-d9 (ET-d9), L-hercynine, L-hercynine-d9, S-methyl-ET, and ET sulfonate were provided by Tetrahedron (www.tetrahedron.fr) (15). Encapsulated ET (Ergoneine ${ }^{\circledR}$, GMP- 
certified ET) and placebo (99\% microcrystalline cellulose, $1 \%$ magnesium stearate) were also provided by Tetrahedron. Allantoin (5-ureidohydantoin) and allantoin- ${ }^{15} \mathrm{~N}_{4}$ were purchased from Sigma-Aldrich and ICON isotopes, respectively. 8-isoPGF $2 \alpha$, IPF2 $\alpha$-VI-d4, arachidonic acid-d8, and 8 OHdG were purchased from Cayman Chemicals. $8 \mathrm{OHdG}^{-13} \mathrm{C}^{15} \mathrm{~N}_{2}$ was purchased from Toronto Research Chemicals. FASt ${ }^{\circledR}$ clean screen solid-phase extraction (SPE) 96-well plates were from United Chemical Technologies. All other reagents used were purchased from Sigma-Aldrich. ET and placebo were encapsulated by Tetrahedron and repackaged into individual coded bags by RAS pharma (Singapore) under ISO13485 compliance.

\section{Study design and ethics procedures}

The placebo-controlled, double-blinded study was undertaken in healthy human male volunteers ( $n=15 /$ group; Investigational Medicine Unit, National University Health System) aged 21-35 years (inclusive) and randomly assigned to placebo, $5 \mathrm{mg}$ ET, or $25 \mathrm{mg}$ ET groups. A $5 \mathrm{mg}$ ET dose was estimated to be equivalent to one serving of mushrooms (61), whereas the higher dose was five times more, to examine the upper limits of ET uptake. A pre-screening was conducted 2 weeks before the commencement of the study to ensure that subjects met a list of parameters to minimize variables. Two weeks before the commencement, and for the entire duration of the study, subjects were requested to abstain from foods containing high levels of ET, for example, mushrooms, liver, beans, etc., to minimize variability in ET levels due to diet, and also from antioxidant tablets or other supplements. All the procedures were approved by the $\mathrm{Na}$ tional Healthcare Group, Domain Specific Review Board (protocol number: 2013/01074).

\section{Screening parameters}

Healthy male volunteers of Chinese ethnicity, aged 21-35 years (inclusive), were recruited for initial screening. After the briefing and informed consent, the recruited subjects were screened for inclusion criteria to minimize variability. Men were selected, since gender differences in ET accumulation were previously observed in rats (36), probably related to testosterone levels, and furthermore, men have been suggested to have higher oxidative stress levels than women (59). Subjects were required to have a body mass index of between 18 and 25, a blood pressure range of 115-135 systolic and 60-85 diastolic, total cholesterol $<240 \mathrm{mg} / \mathrm{dl}$, and low-density lipoprotein-cholesterol $<160 \mathrm{mg} / \mathrm{dl}$. Subjects with pre-existing medical conditions (i.e., history of cardiovascular complications, diabetes, hypertension, hypercholesterolemia, anemia or other hematological conditions, chronic inflammatory conditions, or any infectious disease or fever) were excluded from the study. In addition, subjects failing to meet healthy reference values for liver and renal function tests, with a history of cigarette smoking, drug or alcohol abuse, on any prescription medication, or involved in another study requiring compound administration in the 30 days before the screening, were excluded from the study.

\section{ET administration, study compliance, and blood and urine sampling}

Subjects were randomly allocated to one of the three administration groups: placebo, $5 \mathrm{mg}$ ET, or $25 \mathrm{mg}$ ET. Placebo or ET capsules (Tetrahedron; GMP certified; identical encapsulation; and blinded by the manufacturer) were orally administered every morning for 7 days. Capsules were administered at the clinic after blood and urine sampling on days 1,3 , and 5. Take-home capsules were provided for days 2, 4, 6, and 7. Subjects returned the empty package, noting consumption time, to verify compliance. Other aspects of study compliance, including review of abstinence from ETrich foods, and administration of any medications were conducted during study visits. Blood and urine samples were collected on days $1,3,5,8,14,21,28$, and 35 (Fig. 2). Venous blood ( $8 \mathrm{ml}$ ) was collected in $\mathrm{K}_{2}$ EDTA vacutainers (Becton Dickinson). Aliquots $(250 \mu \mathrm{l})$ of whole blood were transferred to $1.5 \mathrm{ml}$ tubes and stored at $-80^{\circ} \mathrm{C}$. Plasma was obtained by centrifugation at $2500 \mathrm{rpm}$ for $15 \mathrm{~min}$, stored in $250 \mu \mathrm{l}$ aliquots with butylated hydroxytoluene $(16 \mu M)$ and indomethacin $(20 \mu M)$, and stored at $-80^{\circ} \mathrm{C}$. Urine samples were stored in $2 \mathrm{ml}$ aliquots at $-80^{\circ} \mathrm{C}$.

\section{Sample preparation for ET, S-methyl ET, hercynine, and allantoin measurement}

Samples were thawed on ice and vortexed briefly to ensure homogeneity. For whole blood, $20 \mu \mathrm{l}$ was added to $200 \mu \mathrm{l}$ of ultrapure water (Sartorius) containing ET-d9 and hercynined9. Samples were heated at $80^{\circ} \mathrm{C}$ for $15 \mathrm{~min}$ and centrifuged (14,000 g, $15 \mathrm{~min})$. Two hundred microliters of supernatants were added to $1 \mathrm{ml}$ cold acetone for $2 \mathrm{~h}$ at $-20^{\circ} \mathrm{C}$. Samples were centrifuged, and the acetone in the supernatant was removed by using a vacuum evaporator. The aqueous supernatants were transferred to silanized glass inserts with vials (Agilent CrossLab) for LC-MS/MS measurement.

For plasma, $30 \mu \mathrm{l}$ of sample was mixed with $127 \mu \mathrm{l}$ methanol containing ET-d9, hercynine-d9, and allantoin- ${ }^{15} \mathrm{~N}_{4}$ internal standards. Samples were vortexed and incubated at $-20^{\circ} \mathrm{C}$ for $2 \mathrm{~h}$. Samples were centrifuged, and supernatants were transferred to silanized inserts for analysis.

For urine, after thawing, samples were centrifuged to remove precipitated debris. Supernatants $(15 \mu \mathrm{l})$ were mixed with $8 \mu \mathrm{l}$ of internal standards containing ET-d9, hercynine$\mathrm{d} 9$, and allantoin- ${ }^{15} \mathrm{~N}_{4}$ and $285 \mu$ l of methanol. Samples were treated as per the plasma samples described earlier.

\section{Urinary, plasma, and whole blood ET, S-methyl-ET, and hercynine measurement by LC-MS/MS}

LC-MS/MS was performed by using an Agilent 1200 LC coupled to a 6460-QQQ mass spectrometer (Agilent Technologies). Samples were kept at $10^{\circ} \mathrm{C}$ in the autosampler. Samples $(5 \mu \mathrm{l})$ were injected onto a Cogent DiamondHydride column $(4 \mu \mathrm{m}, 150 \times 2.1 \mathrm{~mm}, 100 \AA$; MicroSolv Technology Corporation) that was maintained at $30^{\circ} \mathrm{C}$. The mobile phase was $100 \%$ acetonitrile (solvent A; solvA) and $0.1 \%$ formic acid (solvent B; solvB). Chromatographic separation was achieved by using a gradient elution at $0.4 \mathrm{ml} / \mathrm{min}$ from $25 \%$ solvB at $1 \mathrm{~min}$ to $40 \%$ solvB over $3 \mathrm{~min}$ to elute ET. A further increase to $90 \%$ solvB over 3 min was applied to elute S-methyl-ET and hercynine. This was maintained for $1.25 \mathrm{~min}$ before re-equilibration of the column at $25 \%$ solvB for $2.5 \mathrm{~min}$. The retention times for ET, hercynine, and Smethyl ET were 3.6, 7.1, and 7.2 min, respectively.

MS was carried out under positive ion, electrospray ionization (ESI) mode, using multiple reaction monitoring 
(MRM) for quantification of specific target ions. Capillary voltage was $3200 \mathrm{~V}$, and gas temperature was $350^{\circ} \mathrm{C}$. Nitrogen sheath gas pressure for nebulizing the sample was $50 \mathrm{psi}$, with a gas flow rate of $12.5 \mathrm{l} / \mathrm{min}$. Ultra-high-purity nitrogen was used as collision gas.

\section{Urinary and plasma allantoin measurement by $L C-M S / M S$}

Five-microliter processed samples were injected onto a Hypercarb column $(5 \mu \mathrm{m}, 100 \times 4.6 \mathrm{~mm}$; Thermo Scientific $)$ that was maintained at $30^{\circ} \mathrm{C}$. Allantoin was separated by gradient elution at $0.6 \mathrm{ml} / \mathrm{min}$ from $90 \%$ solvB $(0.1 \%$ formic acid) and $10 \%$ solvA (acetonitrile), to $10 \%$ solvB over $5 \mathrm{~min}$. This was maintained for $1 \mathrm{~min}$ before returning to $90 \%$ solvB to equilibrate the column for $2.5 \mathrm{~min}$. Allantoin was eluted at $2.7 \mathrm{~min}$. All MS parameters were the same as for ET analysis, except capillary voltage, which was set at $5000 \mathrm{~V}$.

\section{Urinary $80 H d G$ measurement by $L C-M S / M S$}

Urine samples were thawed and centrifuged to remove debris before the sample clean-up. Five hundred microliters of urine were mixed with $5 \mu \mathrm{lof} 1 \mathrm{ng} / \mathrm{ml} 8 \mathrm{OHdG}^{-13} \mathrm{C}^{15} \mathrm{~N}_{2}$ and passed through Clean Screen FASt 96-well $100 \mathrm{mg}$ SPE plates. Twenty-five microliters of the resulting samples were injected onto a Synergi Polar Reverse-Phase column ( $80 \AA$ A, $4 \mu \mathrm{m}, 100 \times 2.0 \mathrm{~mm}$; Phenomenex). Chromatographic separation was achieved by using isocratic elution at $0.6 \mathrm{ml} / \mathrm{min}$ using $95 \%$ of solvB ( $0.1 \%$ formic acid) and 5\% of solvA (acetonitrile) for $2 \mathrm{~min}$, after which the column was washed using $10 \%$ of solvB for $2.5 \mathrm{~min}$, before returning to $95 \%$ of solvB to equilibrate the column for $3.5 \mathrm{~min}$. 8OHdG was eluted at $1.55 \mathrm{~min}$. All MS parameters were the same as for ET analysis, except capillary voltage, which was set at $3000 \mathrm{~V}$.

\section{Urinary $F_{2}-I s o P$ measurement by $L C-M S / M S$}

$\mathrm{F}_{2}$-IsoP (8-iso-PGF2 $\alpha$ ) and $\mathrm{F}_{2}$-IsoP-d4 (IPF2 $\alpha$-VI-d4) were obtained from Cayman. Standards were dissolved in $1: 1: 2$, acetonitrile:methanol:water with $0.01 \%$ acetic acid. A standard curve was generated from 5 to $200 \mathrm{ng} / \mathrm{ml}$ by serial dilution in elution buffer.

Three milliliters of urine were mixed with $25 \mathrm{ng}$ internal standards ( $\mathrm{F}_{2}$-IsoP-d4), and cleaned by SPE using Oasis MAX 3cc mixed-mode cartridges. Briefly, urine samples were passed through Oasis MAX columns, and they were preconditioned with $2 \mathrm{ml}$ methanol and $2 \mathrm{ml} 0.1 \%$ formic acid by gravity elution. Columns were washed with $2 \mathrm{ml} 2 \%$ ammonium hydroxide followed by $2 \mathrm{ml}$ methanol. The columns were dried under negative pressure before washing with $2 \mathrm{ml}$

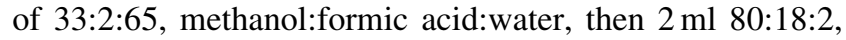
hexane:ethyl acetate:formic acid, and finally eluted with $1.5 \mathrm{ml}$ 53:45:2, ethyl acetate:hexane:formic acid. The eluents were dried under a stream of $\mathrm{N}_{2}$ gas and resuspended in $0.01 \%$ acetic acid.

Twenty-five microliters of the resulting samples were injected onto a PFP reversed-phase Accucore column $(2.6 \mu \mathrm{m}$, $100 \times 2.1 \mathrm{~mm}$; Thermo Scientific). Chromatographic separation was achieved by gradient elution at $0.4 \mathrm{ml} / \mathrm{min}$ from $70 \%$ solvB ( $0.01 \%$ acetic acid), 30\% solvA (1:1 acetonitrile: methanol with $0.01 \%$ acetic acid) at 2 min to $68 \%$ solvB in
10 min, after which the column was washed by using $95 \%$ of solvA for $2.5 \mathrm{~min}$, before returning to $70 \%$ of solvB to equilibrate the column for $2.5 \mathrm{~min}$. $\mathrm{F}_{2}$-IsoPs were eluted at $7.25 \mathrm{~min}$.

MS was carried out under negative ion ESI and MRM mode, with a capillary voltage of $5000 \mathrm{~V}$. All other parameters were as previously described for ET analysis.

\section{Transitions and MS parameters}

Precursor to product ion transitions and fragmentor voltages $(\mathrm{V}) /$ collision energies $(\mathrm{eV})$ for each compound were as follows: ET; $230.1 \rightarrow 186,103 \mathrm{~V} / 9 \mathrm{eV}$, ET-d9; $239.1 \rightarrow$ $195.1,98 \mathrm{~V} / 9 \mathrm{eV}$, and hercynine; $198.1 \rightarrow 95.1,94 \mathrm{~V} / 21 \mathrm{eV}$, and hercynine-d9; $207.2 \rightarrow 95.1,97 \mathrm{~V} / 21 \mathrm{eV}$, and S-methylET; $244.1 \rightarrow 141,92 \mathrm{~V} / 17 \mathrm{eV}$, and allantoin; $159 \rightarrow 116$, $70 \mathrm{~V} / 2 \mathrm{eV}$, and allantoin $-{ }^{15} \mathrm{~N}_{4} ; 161 \rightarrow 118,70 \mathrm{~V} / 2 \mathrm{eV}$, and $8 \mathrm{OHdG} ; 284 \rightarrow 161,80 \mathrm{~V} / 10 \mathrm{eV}$, and $8 \mathrm{OHdG}^{13} \mathrm{C}^{15} \mathrm{~N}_{2}$; $287 \rightarrow 171,80 \mathrm{~V} / 10 \mathrm{eV}$, and $\mathrm{F}_{2}$-IsoP; $353.2 \rightarrow 193.2,143 \mathrm{~V} /$ $24 \mathrm{eV}$, and $\mathrm{F}_{2}$-IsoP-d4; and $357.2 \rightarrow 197.2,143 \mathrm{~V} / 24 \mathrm{eV}$.

\section{Urinary creatinine assay}

The Jaffe method was used. Briefly, $15 \mu$ l diluted urine were mixed with $125 \mu$ l creatinine color reagent $(0.6 \%$ picric acid in water, $0.2 M$ phosphate buffer $\mathrm{pH} 7.4,1.6 \%$ sodium dodecyl sulfate) and $25 \mu \mathrm{l} 1 \mathrm{M} \mathrm{NaOH}$. Samples were mixed for $10 \mathrm{~min}$ before measuring absorbance at $500 \mathrm{~nm}$ (initial) by using a microplate reader (Synergy BioTek). Then, $5 \mu$ of $60 \%$ acetic acid was added and samples were mixed for $5 \mathrm{~min}$ before measuring absorbance at $500 \mathrm{~nm}$ (final). The absorbance was recorded as a difference between the initial and final reading and quantified relative to creatinine standards $(20-100 \mu \mathrm{g} / \mathrm{ml})$.

\section{Protein carbonyl assay}

Protein carbonyl contents in the plasma samples were analyzed by using a commercial assay kit according to the manufacturer's protocol with modifications (Sigma-Aldrich). Briefly, three samples from the same group were pooled together and diluted 1:7 with phosphate-buffered saline (PBS). Total protein of the diluted samples was quantified (DC protein assay; BioRad) to ensure that concentrations were between 15 and $20 \mathrm{mg} / \mathrm{ml}$. One hundred microliters of diluted plasma samples were added to 2,4-dinitrophenylhydrazine solution and incubated at $25^{\circ} \mathrm{C}$ for $15 \mathrm{~min}$; then, $30 \mu \mathrm{l}$ of $100 \% \mathrm{w} / \mathrm{v}$ trichloroacetic acid solution were added to precipitate proteins. Samples were incubated on ice for $5 \mathrm{~min}$ and centrifuged at $13,000 \mathrm{~g}$ for $5 \mathrm{~min}$ at $4^{\circ} \mathrm{C}$. Supernatants were removed, and the pellets were washed with cold acetone and incubated at $-20^{\circ} \mathrm{C}$ for $10 \mathrm{~min}$ before centrifugation. The acetone was removed, and the resultant pellets were resolubilized in $200 \mu \mathrm{l}$ of $6 \mathrm{M}$ guanidine hydrochloride. One hundred microliters of the samples was transferred to a microtiter plate, and the absorbance at $375 \mathrm{~nm}$ was measured. Protein carbonyl contents were normalized to total protein.

\section{CRP enzyme-linked immunosorbent assay}

Microtiter plates (96-well; Nunc-Immun; Nalgene) were coated with $100 \mu \mathrm{l} 5 \mu \mathrm{g} / \mathrm{ml}$ anti-human CRP monoclonal antibody (ab8278; Abcam) in carbonate buffer ( $\mathrm{pH} 9.6)$, overnight at $4^{\circ} \mathrm{C}$. Wells were washed twice with PBS-T $(0.1 \% \mathrm{v} / \mathrm{v})$ and $100 \mu \mathrm{l}$ of diluted (1:500 or 1:4000) plasma samples or CRP 
standards were added. Plates were incubated for $2 \mathrm{~h}$ at $25^{\circ} \mathrm{C}$ on an orbital shaker $(200 \mathrm{rpm})$; then, they were washed thrice with PBS-T. One hundred microliters of horseradish peroxidaseconjugated anti-human-CRP antibody $(0.5 \mu \mathrm{g} / \mu \mathrm{l} ; \mathrm{ab} 24461)$ were added, and plates were incubated at room temperature for $1 \mathrm{~h}$. The plates were washed four times with PBS-T, and $100 \mu \mathrm{l}$ of $3,3^{\prime}, 5,5^{\prime}$-tetramethylbenzidine substrate were added to each well. Plates were incubated in the dark for $15 \mathrm{~min}$, and $100 \mu \mathrm{l}$ $2 \mathrm{M} \mathrm{H}_{2} \mathrm{SO}_{4}$ were added to stop further color development. Plates were read at $450 \mathrm{~nm}$ after subtracting reference readings at $570 \mathrm{~nm}$, and concentrations were calculated from a calibration curve.

\section{Clinical parameters}

Blood samples ( $\sim 4 \mathrm{ml}$ venous blood in $\mathrm{K}_{2}$ EDTA and $\mathrm{NaF}$ vacutainers) during screening and final visits were sent to National University Hospital Referral Laboratory for analyses. Samples were analyzed for liver function (albumin, bilirubin, alanine transaminase, aspartate transaminase, alkaline phosphatase, and lactate dehydrogenase), fasting glucose, cholesterol (low/high-density lipoprotein), triglycerides, and gamma-glutamyl transpeptidase (GGT). Blood samples from the final visit were again monitored for liver function, cholesterol, triglycerides, and GGT.

\section{Statistical analysis}

Data were tabulated by using Microsoft Excel (Microsoft Corporation). Graphs and statistical analyses were created/ performed by using Graphpad Prism version5 (Graphpad). Data are expressed as mean \pm standard error of the mean, with $p<0.05$ considered statistically significant. Pearson's correlation coefficient was used to calculate associations between variables with $p<0.05$, indicating significance of the correlation coefficient.

\section{Acknowledgments}

The authors wish to thank Tetrahedron (14 avenue de l'Opera, Paris, France) for providing the encapsulated Lergothioneine and placebo, and L-ergothioneine-d9, hercynine, hercynine-d9, S-methyl-ergothioneine, and ergothioneine sulfonate analytical standards used in this study. The authors also thank the National Medical Research Council of Singapore (NMRC/1264/2010/082/12) for providing financial support.

\section{Author Disclosure Statement}

No competing financial interests exist.

\section{References}

1. Akanmu D, Cecchini R, Aruoma OI, and Halliwell B. The antioxidant action of ergothioneine. Arch Biochem Biophys 288: 10-16, 1991.

2. Aruoma OI, Spencer JP, and Mahmood N. Protection against oxidative damage and cell death by the natural antioxidant ergothioneine. Food Chem Toxicol 37: 10431053, 1999.

3. Aruoma OI, Whiteman M, England TG, and Halliwell B. Antioxidant action of ergothioneine: assessment of its ability to scavenge peroxynitrite. Biochem Biophys Res Commun 231: 389-391, 1997.
4. Askari A and Melville DB. The reaction sequence in ergothioneine biosynthesis: hercynine as an intermediate. $J$ Biol Chem 237: 1615-1618, 1962.

5. Asmus KD, Bensasson RV, Bernier JL, Houssin R, and Land EJ. One-electron oxidation of ergothioneine and analogues investigated by pulse radiolysis: redox reaction involving ergothioneine and vitamin C. Biochem J 315: 625-629, 1996.

6. Bedirli A, Sakrak O, Muhtaroglu S, Soyuer I, Guler I, Riza Erdogan A, and Sozuer EM. Ergothioneine pretreatment protects the liver from ischemia-reperfusion injury caused by increasing hepatic heat shock protein 70. J Surg Res 122: 96-102, 2004.

7. Calabrese V, Cornelius C, Dinkova-Kostova AT, Iavicoli I, Di Paola R, Koverech A, Cuzzocrea S, Rizzarelli E, and Calabrese EJ. Cellular stress responses, hormetic phytochemicals and vitagenes in aging and longevity. Biochim Biophys Acta 1822: 753-783, 2012.

8. Calabrese V, Cornelius C, Trovato A, Cavallaro M, Mancuso C, Di Rienzo L, Condorelli D, De Lorenzo A, and Calabrese EJ. The hormetic role of dietary antioxidants in free radical-related diseases. Curr Pharm Des 16: 877-883, 2010.

9. Cheah I, Feng L, Tang RMY, Lim KHM, and Halliwell B. Ergothioneine levels in an elderly population decrease with age and incidence of cognitive decline; a risk factor for neurodegeneration? Biochem Biophys Res Commun 478: 162-167, 2016.

10. Cheah IK and Halliwell B. Ergothioneine; antioxidant potential, physiological function and role in disease. Biochim Biophys Acta 1822: 784-793, 2012.

11. Cheah IK, Ong RL, Gruber J, Yew TS, Ng LF, Chen CB, and Halliwell B. Knockout of a putative ergothioneine transporter in Caenorhabditis elegans decreases lifespan and increases susceptibility to oxidative damage. Free Radic Res 47: 1036-1045, 2013.

12. Cheah IK, Tang R, Ye P, Yew TS, Lim KH, and Halliwell B. Liver ergothioneine accumulation in a guinea pig model of non-alcoholic fatty liver disease. A possible mechanism of defence? Free Radic Res 50: 14-25, 2016.

13. Colognato R, Laurenza I, Fontana I, Coppede F, Siciliano G, Coecke S, Aruoma OI, Benzi L, and Migliore L. Modulation of hydrogen peroxide-induced DNA damage, MAPKs activation and cell death in PC12 by ergothioneine. Clin Nutr 25: 135-145, 2006.

14. Deiana M, Rosa A, Casu V, Piga R, Assunta Dessi M, and Aruoma OI. L-ergothioneine modulates oxidative damage in the kidney and liver of rats in vivo: studies upon the profile of polyunsaturated fatty acids. Clin Nutr 23: 183193, 2004.

15. Erdelmeier I, Daunay S, Lebel R, Farescour L, and Yadan JC. Cysteine as a sustainable sulfur reagent for the protecting-group-free synthesis of sulfur-containing amino acids: biomimetic synthesis of L-ergothioneine in water. Green Chem 14: 2256-2265, 2012.

16. Ey J, Schomig E, and Taubert D. Dietary sources and antioxidant effects of ergothioneine. J Agric Food Chem 55: 6466-6474, 2007.

17. Forster R, Spezia F, Papineau D, Sabadie C, Erdelmeier I, Moutet M, and Yadan JC. Reproductive safety evaluation of L-ergothioneine. Food Chem Toxicol 80: 85-91, 2015.

18. Genghof DS. Biosynthesis of ergothioneine and hercynine by fungi and Actinomycetales. J Bacteriol 103: 475-478, 1970 . 
19. Genghof DS and Vandamme O. Biosynthesis of ergothioneine and hercynine by mycobacteria. J Bacteriol 87: 852$862,1964$.

20. Grigat S, Harlfinger S, Pal S, Striebinger R, Golz S, Geerts A, Lazar A, Schomig E, and Grundemann D. Probing the substrate specificity of the ergothioneine transporter with methimazole, hercynine, and organic cations. Biochem Pharmacol 74: 309-316, 2007.

21. Grootveld M and Halliwell B. Measurement of allantoin and uric acid in human body fluids. A potential index of free-radical reactions in vivo? Biochem $J$ 243: 803-808, 1987.

22. Gruber J, Tang SY, Jenner AM, Mudway I, Blomberg A, Behndig A, Kasiman K, Lee CY, Seet RC, Zhang W, Chen C, Kelly FJ, and Halliwell B. Allantoin in human plasma, serum, and nasal-lining fluids as a biomarker of oxidative stress: avoiding artifacts and establishing real in vivo concentrations. Antioxid Redox Signal 11: 1767-1776, 2009.

23. Grundemann D, Harlfinger S, Golz S, Geerts A, Lazar A, Berkels R, Jung N, Rubbert A, and Schomig E. Discovery of the ergothioneine transporter. Proc Natl Acad Sci U S A 102: 5256-5261, 2005.

24. Halliwell B. Why and how should we measure oxidative DNA damage in nutritional studies? How far have we come? Am J Clin Nutr 72: 1082-1087, 2000.

25. Halliwell B, Cheah IK, and Drum CL. Ergothioneine, an adaptive antioxidant for the protection of injured tissues? A hypothesis. Biochem Biophys Res Commun 470: 245-250, 2016.

26. Halliwell B and Gutteridge JM. Free Radicals in Biology and Medicine (Fifth Edition). Oxford, United Kingdom: Clarendon Press, 2015.

27. Hanlon DP. Interaction of ergothioneine with metal ions and metalloenzymes. J Med Chem 14: 1084-1087, 1971.

28. Hartman PE, Hartman Z, and Citardi MJ. Ergothioneine, histidine, and two naturally occurring histidine dipeptides as radioprotectors against gamma-irradiation inactivation of bacteriophages T4 and P22. Radiat Res 114: 319-330, 1988.

29. Heath $\mathrm{H}$ and Toennies $\mathrm{G}$. The preparation and properties of ergothioneine disulphide. Biochem J 68: 204-210, 1958.

30. Hseu YC, Lo HW, Korivi M, Tsai YC, Tang MJ, and Yang HL. Dermato-protective properties of ergothioneine through induction of Nrf2/ARE-mediated antioxidant genes in UVA-irradiated Human keratinocytes. Free Radic Biol Med 86: 102-117, 2015.

31. Jacob C. A scent of therapy: pharmacological implications of natural products containing redox-active sulfur atoms. Nat Prod Rep 23: 851-863, 2006.

32. Kato Y, Kubo Y, Iwata D, Kato S, Sudo T, Sugiura T, Kagaya T, Wakayama T, Hirayama A, Sugimoto M, Sugihara K, Kaneko S, Soga T, Asano M, Tomita M, Matsui T, Wada M, and Tsuji A. Gene knockout and metabolome analysis of carnitine/organic cation transporter OCTN1. Pharm Res 27: 832-840, 2010.

33. Laurenza I, Colognato R, Migliore L, Del Prato S, and Benzi L. Modulation of palmitic acid-induced cell death by ergothioneine: evidence of an anti-inflammatory action. Biofactors 33: 237-247, 2008.

34. Lee CY, Huang SH, Jenner AM, and Halliwell B. Measurement of $\mathrm{F}_{2}$-isoprostanes, hydroxyeicosatetraenoic products, and oxysterols from a single plasma sample. Free Radic Biol Med 44: 1314-1322, 2008.

35. Li RW, Yang C, Sit AS, Kwan YW, Lee SM, Hoi MP, Chan SW, Hausman M, Vanhoutte PM, and Leung GP. Uptake and protective effects of ergothioneine in human endothelial cells. J Pharmacol Exp Ther 350: 691-700, 2014.

36. Mackenzie JB and Mackenzie CG. The effect of age, sex, and androgen on blood ergothioneine. J Biol Chem 225: 651-657, 1957.

37. Maeda T, Hirayama M, Kobayashi D, Miyazawa K, and Tamai I. Mechanism of the regulation of organic cation/ carnitine transporter 1 (SLC22A4) by rheumatoid arthritisassociated transcriptional factor RUNX1 and inflammatory cytokines. Drug Metab Dispos 35: 394-401, 2007.

38. Markova NG, Karaman-Jurukovska N, Dong KK, Damaghi $\mathrm{N}$, Smiles KA, and Yarosh DB. Skin cells and tissue are capable of using L-ergothioneine as an integral component of their antioxidant defense system. Free Radic Biol Med 46: 1168-1176, 2009.

39. Mayumi T, Kawano H, Sakamoto Y, Suehisa E, Kawai Y, and Hama T. Studies on ergothioneine. V. Determination by high performance liquid chromatography and application to metabolic research. Chem Pharm Bull (Tokyo) 26: 3772-3778, 1978.

40. Melville DB, Horner WH, and Lubschez R. Tissue ergothioneine. J Biol Chem 206: 221-228, 1954.

41. Milne GL, Yin HY, Brooks JD, Sanchez S, Roberts LJ, and Morrow JD. Quantification of $\mathrm{F}_{2}$-isoprostanes in biological fluids and tissues as a measure of oxidant stress. Methods Enzymol 433: 113-126, 2007.

42. Motohash.N, Mori I, Sugiura Y, and Tanaka H. Metalcomplexes of ergothioneine. Chem Pharm Bull 22: 654657, 1974.

43. Nakamura T, Sugiura S, Kobayashi D, Yoshida K, Yabuuchi H, Aizawa S, Maeda T, and Tamai I. Decreased proliferation and erythroid differentiation of K562 cells by siRNA-induced depression of OCTN1 (SLC22A4) transporter gene. Pharm Res 24: 1628-1635, 2007.

44. Obayashi K, Kurihara K, Okano Y, Masaki H, and Yarosh DB. L-Ergothioneine scavenges superoxide and singlet oxygen and suppresses TNF-alpha and MMP-1 expression in UV-irradiated human dermal fibroblasts. J Cosmet Sci 56: 17-27, 2005.

45. Pfeiffer C, Bach M, Bauer T, Campos da Ponte J, Schomig $\mathrm{E}$, and Grundemann D. Knockout of the ergothioneine transporter ETT in zebrafish results in increased 8oxoguanine levels. Free Radic Biol Med 83: 178-185, 2015.

46. Rahman I, Gilmour PS, Jimenez LA, Biswas SK, Antonicelli F, and Aruoma OI. Ergothioneine inhibits oxidative stress- and TNF-alpha-induced NF-kappa B activation and interleukin-8 release in alveolar epithelial cells. Biochem Biophys Res Commun 302: 860-864, 2003.

47. Redford-Ellis M and Gowenlock AH. Studies on the reaction of chloromethane with human blood. Acta Pharmacol Toxicol (Copenh) 30: 36-48, 1971.

48. Repine JE and Elkins ND. Effect of ergothioneine on acute lung injury and inflammation in cytokine insufflated rats. Prev Med 54 Suppl: S79-S82, 2012.

49. Sakrak O, Kerem M, Bedirli A, Pasaoglu H, Akyurek N, Ofluoglu E, and Gultekin FA. Ergothioneine modulates proinflammatory cytokines and heat shock protein 70 in mesenteric ischemia and reperfusion injury. J Surg Res 144: 36-42, 2008.

50. Sakrak Ö, Kerem M, Bedirli A, Pasaoğlu H, Alper M, Ofluoğlu E, and Yilmaz TU. Ergothioneine prevents acute lung injury in mesenteric ischemia and reperfusion injury in rats. J Crit Care 23: 268-269, 2008. 
51. Schauss AG, Beres E, Vertesi A, Frank Z, Pasics I, Endres J, Aruoma OI, and Hirka G. The effect of ergothioneine on clastogenic potential and mutagenic activity: genotoxicity evaluation. Int J Toxicol 30: 405-409, 2011.

52. Schauss AG, Vertesi A, Endres JR, Hirka G, Clewell A, Qureshi I, and Pasics I. Evaluation of the safety of the dietary antioxidant ergothioneine using the bacterial reverse mutation assay. Toxicology 278: 39-45, 2010.

53. Seet RC, Lee CY, Loke WM, Huang SH, Huang H, Looi WF, Chew ES, Quek AM, Lim EC, and Halliwell B. Biomarkers of oxidative damage in cigarette smokers: which biomarkers might reflect acute versus chronic oxidative stress? Free Radic Biol Med 50: 1787-1793, 2011.

54. Servillo L, Castaldo D, Casale R, D'Onofrio N, Giovane A, Cautela D, and Balestrieri ML. An uncommon redox behavior sheds light on the cellular antioxidant properties of ergothioneine. Free Radic Biol Med 79: 228-236, 2015.

55. Song TY, Lin HC, Chen CL, Wu JH, Liao JW, and Hu ML. Ergothioneine and melatonin attenuate oxidative stress and protect against learning and memory deficits in C57BL/6 J mice treated with D-galactose. Free Radic Res 48: 10491060, 2014.

56. Tanret C. Sur une base nouvelle retiree du seigle ergote, l'ergothioneine. Compt Rende 149: 222-224, 1909.

57. Toh DS, Cheung FS, Murray M, Pern TK, Lee EJ, and Zhou F. Functional analysis of novel variants in the organic cation/ergothioneine transporter 1 identified in Singapore populations. Mol Pharm 10: 2509-2516, 2013.

58. Toh DS, Limenta LM, Yee JY, Wang LZ, Goh BC, Murray $\mathrm{M}$, and Lee EJ. Effect of mushroom diet on pharmacokinetics of gabapentin in healthy Chinese subjects. $\mathrm{Br} \mathrm{J}$ Clin Pharmacol 78: 129-134, 2014.

59. Vina J, Gambini J, Lopez-Grueso R, Abdelaziz KM, Jove $\mathrm{M}$, and Borras C. Females live longer than males: role of oxidative stress. Curr Pharm Des 17: 3959-3965, 2011.

60. Violi F and Pignatelli P. Clinical application of NOX activity and other oxidative biomarkers in cardiovascular disease: a critical review. Antioxid Redox Signal 23: 514532, 2015.

61. Weigand-Heller AJ, Kris-Etherton PM, and Beelman RB. The bioavailability of ergothioneine from mushrooms (Agaricus bisporus) and the acute effects on antioxidant capacity and biomarkers of inflammation. Prev Med 54 Suppl: S75-S78, 2012.

62. Wu LL, Chiou CC, Chang PY, and Wu JT. Urinary 8OHdG: a marker of oxidative stress to DNA and a risk factor for cancer, atherosclerosis and diabetics. Clin Chim Acta 339: 1-9, 2004.

63. Yang NC, Lin HC, Wu JH, Ou HC, Chai YC, Tseng CY, Liao JW, and Song TY. Ergothioneine protects against neuronal injury induced by beta-amyloid in mice. Food Chem Toxicol 50: 3902-3911, 2012.

64. Zengi O, Karakas A, Ergun U, Senes M, Inan L, and Yucel D. Urinary 8-hydroxy-2'-deoxyguanosine level and plasma paraoxonase 1 activity with Alzheimer's disease. Clin Chem Lab Med 50: 529-534, 2012.

65. Zhu BZ, Mao L, Fan RM, Zhu JG, Zhang YN, Wang J, Kalyanaraman B, and Frei B. Ergothioneine prevents copper-induced oxidative damage to DNA and protein by forming a redox-inactive ergothioneine-copper complex. Chem Res Toxicol 24: 30-34, 2011.

Address correspondence to: Prof. Barry Halliwell

Centre for Life Sciences National University of Singapore 28 Medical Drive, \#04-19A Singapore 117456

Singapore

E-mail: bchbh@nus.edu.sg

Date of first submission to ARS Central, June 8, 2016; date of final revised submission, July 22, 2016; date of acceptance, August 3, 2016.

$\begin{aligned} & \text { Abbreviations Used } \\ & 8 \mathrm{OHdG}= \text { - } \text {-hydroxy-2 }{ }^{\prime} \text {-deoxyguanosine } \\ & \mathrm{CRP}= \mathrm{C} \text {-reactive protein } \\ & \mathrm{ESI}=\text { electrospray ionization } \mathrm{ET}=\text { L-ergothioneine } \\ & \mathrm{ET}-\mathrm{d} 9=\text { L-ergothioneine-d } 9 \\ & \mathrm{~F}_{2}-\mathrm{IsoP}=\mathrm{F}_{2} \text {-isoprostanes } \\ & \mathrm{GGT}=\text { gamma-glutamyl transpeptidase } \\ & \mathrm{GSH}=\text { reduced glutathione } \\ & \mathrm{IL}=\text { interleukin } \\ & \mathrm{LC}-\mathrm{MS} / \mathrm{MS}=\text { liquid chromatography tandem mass } \\ & \mathrm{MRM}=\text { multiple reaction monitoring } \\ & \mathrm{MS}=\text { mass spectrometry } \\ & \mathrm{NOX}=\text { NADPH oxidase } 1 \\ & \mathrm{OCTN} 1=\text { organic cation transporter novel type- } 1 \\ & \mathrm{PBS}=\text { phosphate-buffered saline } \\ & \mathrm{ROS}=\text { reactive oxygen species } \\ & \text { solvA/B }=\text { solvent A/B } \\ & \mathrm{SPE}=\text { solid-phase extraction }\end{aligned}$

